\title{
Paclobutrazol Residue Determination in Potato and Soil Using Low Temperature Partition Extraction and Ultrahigh Performance Liquid Chromatography Tandem Mass Spectrometry
}

\author{
Hongcheng Liu, ${ }^{1,2,3}$ Tao Lin,,${ }^{1,2,3}$ Jia Mao, ${ }^{4}$ Huan Lu, ${ }^{5}$ Dongshun Yang, ${ }^{1,2,3}$ \\ Jiliang Wang, ${ }^{5}$ and Qiwan $\mathrm{Li}^{1,2,3}$ \\ ${ }^{1}$ Supervision \& Testing Center for Farm Product Quality, Ministry of Agriculture, Kunming, China \\ ${ }^{2}$ Laboratory of Quality \& Safety Risk Assessment for Agro-Product, Ministry of Agriculture, Kunming, China \\ ${ }^{3}$ Institute of Quality Standard and Testing Technology, Yunnan Academy of Agriculture Science, Kunming 650223, China \\ ${ }^{4}$ Institute of Agriculture Environment and Source, Yunnan Academy of Agriculture Science, Kunming 650223, China \\ ${ }^{5}$ Kunming Medical University, Kunming, China
}

Correspondence should be addressed to Qiwan Li; cmliu_0@sina.com

Received 1 May 2015; Revised 3 July 2015; Accepted 8 July 2015

Academic Editor: Juan F. Garcia-Reyes

Copyright (C) 2015 Hongcheng Liu et al. This is an open access article distributed under the Creative Commons Attribution License, which permits unrestricted use, distribution, and reproduction in any medium, provided the original work is properly cited.

\begin{abstract}
A simple, accurate, and highly sensitive analytical method was developed for determining the paclobutrazol residue in potato and soil, the dynamics dissipation in soil. Extraction was carried out by low temperature partitioning and analyzed by ultrahigh performance liquid chromatography tandem mass spectrometry (UHPLC-MS/MS). For a favor extraction yield, the parameters such as temperature and solvent were optimized. The result showed that sample would be easily frozen and separated using acetonitrile under $-20^{\circ} \mathrm{C}$ for $10 \mathrm{~min}$. The limit of detection (LOD) was $0.5 \mu \mathrm{g} / \mathrm{kg}$, and the limit of quantification (LOQ) was 2 and $5 \mu \mathrm{g} / \mathrm{kg}$ for potato and soil, respectively. The influence of paclobutrazol residue in potato was evaluated. The possible contamination of paclobutrazol from surface can be rinsed by distilled water or peeled off, but the paclobutrazol in potato harvest comes mainly from absorption and transport, which could not be removed by peeling. The half-life of paclobutrazol in soil was 20.64 days, and the residue was below $0.22 \mathrm{mg} / \mathrm{kg}$ on 50th day after spraying. According to the risk assessment with Need Maximum Daily Intake (NEDI) and Acceptable Daily Intake (ADI), a Maximum Residue Limit (MRL) of paclobutrazol in potato was recommended as $1.0 \mathrm{mg} / \mathrm{kg}$.
\end{abstract}

\section{Introduction}

Paclobutrazol (chemical structure as in Figure 1) was a plant growth regulator registered for the reduction of terminal growth and pruning volume, the inhibition of gibberellins and sterol biosynthesis, and hence the rate of cell division $[1,2]$. Due to its toxicity, the agreed ADI (Accepted Daily Intake) and ARfD (Acute Reference Dose) were all $0.1 \mathrm{mg} / \mathrm{kg}$ bw/day. According to Reg. number 396/2005 (EC) Annex I, the MRL for paclobutrazol in fruit was $0.5 \mathrm{mg} / \mathrm{kg}$, and the national food safety quality standard (GB 2763-2014, China) was $0.5 \mathrm{mg} / \mathrm{kg}$ in wheat and rice. However, no information was available concerning the residual status and pattern of paclobutrazol in potato. Growth inhibition characteristics had been reported for paclobutrazol with soil drenches, soil sprays, and foliar sprays. Cross-comparisons among these studies were difficult since they were conducted under different growth conditions (field, greenhouse, and growth chamber). Two other factors that influenced the paclobutrazol residues were absorption rate and longevity or persistence of the compound in treated plant tissue and soil [3].

Traditionally, gas chromatography (GC) and gas chromatography-mass spectrometry (GC/MS) was once popular for analyses of paclobutrazol [4], but GC/MS required 


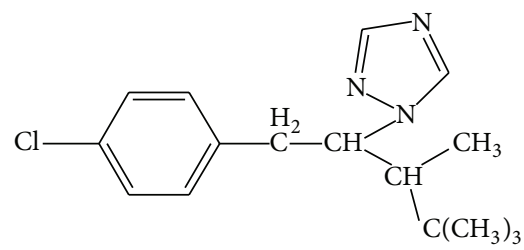

FIGURE 1: The chemical constructure of paclobutrazol.

prederivatization and target compounds may be decomposed by injection at high temperatures [5]. More recently, HPLCbased methods for analyses of paclobutrazol had been published in plant [6-9] and pear pulps [10] using UV detection and different cleanup steps in order to get recoveries of $70 \%$ at the $0.01 \mathrm{mg} / \mathrm{kg}$ level [10]. Thus, using these conventional techniques, it was necessary to perform one or more cleanup steps to decrease interferences and preconcentration steps in order to obtain adequate detection levels.

Nowadays, LC coupled to tandem MS (MS-MS) [11-13] had also been applied to plant growth regulator analysis in fruits as a powerful confirmation tool, improving the sensitivity and reducing the sample pretreatment steps, such as solid phase extraction (SPE) techniques.

Recently, the liquid-liquid extraction with low temperature partitioning (LLE-LTP) was promising for multiresidues analysis since this technique presented some advantages in relation to other extraction techniques, such as practicability, reduced number of steps, and low consumption of organic solvents, as well as being reliable and selective $[11,14]$.

In this study, it was to develop and validate a UHPLCMS/MS method for determination of paclobutrazol in potato and soil, taking advantage of liquid-liquid extraction at low temperature. In addition, the paclobutrazol residue in potato and soil and the dynamics dissipation in soil were investigated through field trials. The purpose of this study was to evaluate the influence of paclobutrazol residue in potato, and a MRL of paclobutrazol in potato was recommended.

\section{Experimental}

2.1. Chemicals and Reagents. A High-Performance Liquid Chromatography- (HPLC-) grade acetonitrile and methanol were obtained from Merck Co. Ltd. (Germany). Sodium chloride and sodium acetate of analytical grade were obtained from the Chemical Reagent Company (Shanghai, China). Highly purified water (Milli-Q, Millipore, Bedford, MA) was used throughout the preparation of the mobile phase.

Paclobutrazol of certified standards (purity higher than 95\%) was purchased from Dr. Ehrenstorfer GmbH (Augsburg, Germany). Stock solution was prepared at $1000 \mathrm{mg} / \mathrm{L}$ in methanol and stored in dark vials at $-20^{\circ} \mathrm{C}$. For the calibration curve, matrix-matched calibration was used with five series concentrations of extraction solution (0.001, 0.01, $0.05,0.1$, and $0.5 \mathrm{mg} / \mathrm{L})$.

2.2. Experimental Design. To investigate the MRL of paclobutrazol in potato and soil, ultimate residue experiments were conducted in experimental fields located in Songming agriculture demonstration garden, Yunnan Province, China, from April 18 to June 29, 2013. The soil was sandy clay loam, with content of sand $46 \%$, clay $28 \%$, organic matter $2.02 \%$, and $\mathrm{pH}$ 6.94. Fields were divided into $30 \mathrm{~m}^{2} / \mathrm{plot}$ with buffer areas. Each treatment was replicated for 3 plots. All cultural practices were applied according to the regional recommendation. The experiments were designed according to NY/T 788-2004 (Guideline on Pesticide Residue Trials) issued by the Ministry of Agriculture, China.

According to the usage guide, paclobutrazol formulation spray application was recommended one time during the early flowering stage of potato (in 45 days). Plants were treated with 3 dosage levels, $40 \mathrm{~g}$ (available ingredient)/ha (the low dosage, recommended dosage), $60 \mathrm{~g}$ (available ingredient)/ha (the middle dosage, 1.5 times the recommended dosage), and $100 \mathrm{~g}$ (available ingredient)/ha (the high dosage, 2.5 times the recommended dosage). Treatments were consisted of foliar sprayed (with or without thick polypropylene soil cover), and the tuber on the paclobutrazol residual soil with $60 \mathrm{~g}$ (available ingredient)/ha, and the control plants were treated with distilled water. Foliar sprays were applied with and without a ground cover to evaluate the impact of foliar adsorption and indirect soil absorption from foliar runoff on soil residue.

To check the possibility of paclobutrazol contamination from surface and peel of tuber, twenty tubers $(4.8 \mathrm{~kg})$ were sprayed with paclobutrazol $(1.0 \mathrm{mg} / \mathrm{L})$, five of which were rinsed with $500 \mathrm{~mL}$ distilled water and $100 \mathrm{~mL}$ acetonitrile; then the rinsing acetonitrile was determined by UHPLCMS/MS after $30 \mathrm{~min}$. Another five samples were peeled; then the peel and pulp were analyzed for comparison with potato harvest.

As reported paper [15], potato was harvested about one month after flowering stage, so the tuber and soil were collected to determine final residue at ten days before harvest (22 days), harvest time (32 days), and eight days after harvest (40 days) after foliar spraying.

To determine dissipation rate of paclobutrazol in soil, nine soil samples were collected after spraying. Soil samples of approximately $500 \mathrm{~g}$ from depth of $0-10 \mathrm{~cm}$ were collected randomly from five points in each plot at $1 \mathrm{~h}, 1,3,7,14,21,32$, 40 , and 50 days after soil spray.

2.3. Sample Preparation. The potatoes peeled were smashed into pieces with a vegetation disintegrator after simple cutting. The soil samples were air-dried, clod broken, mixed, and sieved through a $2 \mathrm{~mm}$ sieve as described by Sharma [16]. These samples were stored at $-20^{\circ} \mathrm{C}$ before being analyzed.

2.4. Extraction Procedure. Soil: $10 \mathrm{~g}$ soil sample was weighed into a $100 \mathrm{~mL}$ centrifuge tube and then $50 \mathrm{~mL}$ acetonitrile was added. The centrifuge tube was extracted in an ultrasonic bath for $10 \mathrm{~min}$ and centrifuged at $3000 \mathrm{~g}$ for $5 \mathrm{~min}$. Afterwards, the tube was stored at low temperature $\left(-20^{\circ} \mathrm{C}\right)$ in refrigerator (Haier, Qingdao, China) for $10 \mathrm{~min}$ to easily separate organic layers. Two-milliliter portions of the organic layer were filtered through $0.2 \mu \mathrm{m}$ membrane filters prior to analysis by UHPLC-MS/MS. 
Potato: $25 \mathrm{~g}$ sample was weighed into a $100 \mathrm{~mL}$ centrifuge tube and extracted with $50 \mathrm{~mL}$ acetonitrile. The same procedure was followed as that described for soil up to UHPLCMS/MS.

2.5. UHPLC-MS/MS Detection. Sample analyses were performed on tandem mass spectrometry AB 4000 (AB Sciex, Ontario, Canada) which consisted of a 1290 ultrahigh performance liquid chromatography (Agilent Technology, USA). A Zorbax Eclipse Plus C18 column $(50 \mathrm{~mm} \times 2.1 \mathrm{~mm}$ i.d., $1.8 \mu \mathrm{m}$ particle size) was employed for the separation of the analyte and was maintained at $30^{\circ} \mathrm{C}$. The mobile phase was comprised of acetonitrile/water containing 0.1 percent formic acid $(78 / 22, v / v)$ and was delivered at a constant flow of $0.3 \mathrm{~mL} / \mathrm{min}$. The injection volume was $1 \mu \mathrm{L}$. The spectral acquisition was operated in positive electron spray ionization mode, and multiple reactions monitoring (MRM) was utilized. The gas temperature was set at $350^{\circ} \mathrm{C}$ with a flow rate of $8.0 \mathrm{~L} / \mathrm{min}$. The nebulizer pressure was $10 \mathrm{~Pa}$. The precursor ion was $m / z 294.2$, and production ion was $m / z 129.0,70.0$ for paclobutrazol, with relative intensity of $4.5 \% / 68 \%$, in which the most intense production ion $\mathrm{m} / z 70.0$ was the quantitative ion, and collision energy and fragmentor were 110 and $50 \mathrm{eV}$, respectively.

\section{Results and Discussion}

3.1. Sample Extraction and Analytical Procedures. Appropriate sample preparation influenced the reliability of the obtained results in a significant way. Solid-Phase Extraction (SPE) was a preferred way to prevent matrix interference, but it was time-consuming with high cost [14]. The advantage of liquid-liquid extraction with low temperature was that the sample components remained in the ice phase, whereas paclobutrazol was extracted by the completely transparent liquid, which was easily obtained and directly analyzed by UHPLC-MS/MS.

As it had been previously indicated, Cho et al. [11] had studied in detail the low temperature extraction of pesticide under $-80^{\circ} \mathrm{C}$. The result showed that the sample would be frozen and separated easily under $-20^{\circ} \mathrm{C}$ to $10 \mathrm{~min}$. So it can be operated under facile condition by home refrigerator.

In order to gain a favorable extraction yield, various organic solvents were studied. The extraction yield of the various solvents for paclobutrazol was listed in the following sequence: acetonitrile (recovery 95\%) > acetone (recovery $86 \%$ ) > dichloromethane (recovery 65\%) $>n$-hexane (recovery $10 \%)$. So the optimal solvent was acetonitrile. Furthermore, the ratio of acetonitrile to the sample showed that the best results were with $2: 1$ (potato) and 5:1 (soil), resulting in $85 \%$ recovery greater than other ratios with $1: 1$ or less.

The tuning solution was introduced into the electrospray ionization (ESI) source by direct infusion. The main ions produced in MS and MS/MS were identified in positive ionization modes. The obtained precursor ions indicated a clear relation between the structure of paclobutrazol and its ability for positive ionization. The precursor ion was $\mathrm{m} / \mathrm{z}$ 294.2, and production ion was $m / z 294.2-129.0$ and 294.270.0 (quantitative ion).
TABLE 1: Recoveries from two samples (five replicates).

\begin{tabular}{lccc}
\hline \multirow{2}{*}{ Sample } & \multirow{2}{*}{ Spiked value $(\mu \mathrm{g} / \mathrm{kg})$} & \multicolumn{2}{c}{ Paclobutrazol } \\
& & RSD (\%) & Recovery (\%) \\
\hline \multirow{3}{*}{ Potato } & 5 & 7.89 & 106.3 \\
& 50 & 6.54 & 87.5 \\
& 100 & 3.62 & 93.0 \\
\multirow{3}{*}{ Soil } & 5 & 10.1 & 104.9 \\
& 50 & 6.51 & 82.9 \\
& 100 & 8.76 & 83.4 \\
\hline
\end{tabular}

The composition of mobile phase can influence the performance of the ionization process in ESI mode. So, different mobile phases (acid, base, and neutral) were tested. The result showed that the response of paclobutrazol can be increased in acid mobile phase $(0.1 \%$ formic acid). The optimized mobile phase was acetonitrile/water containing $0.1 \%$ formic acid $(78 / 22, v / v)$, as shown in Figure 2.

3.2. Valid Method. The matrix effects will suppress the ionization efficiency of paclobutrazol and low recovery. For this reason, residues of paclobutrazol in samples were quantified with matrix-matched five-series standard calibration $(0.001 \mathrm{mg} / \mathrm{L}$, $-0.5 \mathrm{mg} / \mathrm{L})$. The calibration curves showed good linearity with the following equations and relative coefficients: $y=$ $-1.95693 \times 10^{6}+964964 x$, correlation coefficient $R^{2}=$ 0.9976. The instrument detection limit (LOD) and limit of quantification (LOQ) were estimated through ten repetitive injections of standard solution, which can detect at a signalto-noise ratio $(S / N)$ of three multiples and ten multiples, respectively. The LOD value was $0.5 \mu \mathrm{g} / \mathrm{kg}$, and the LOQ values were always $2 \mu \mathrm{g} / \mathrm{kg}$ in the potato and $5 \mu \mathrm{g} / \mathrm{kg}$ in soil. The result of residue experiment can be guaranteed by the LOQ. Samples with concentrations lower than the LOQ were considered not quantifiable. Repeatability and reproducibility were expressed as relative standard deviations (RSD) of retention time (Rt) and peak area (Ar). Reproducibility of Rt and peak area was good for 1 month; all values were $3.4 \%$ (Rt) and $5.2 \%$ (peak area) or less. Furthermore, repeatability of Rt and peak area, which was evaluated on 1 day, proved more satisfactory, with values of $1.5 \%$ (Rt and peak area) or less.

The accuracy of the whole method was evaluated by the development of a recovery study carried out at three concentration levels $(5,50$, and $100 \mu \mathrm{g} / \mathrm{kg})$. All experiments were carried out in quintuplicate at each level (results are shown in Table 1). As it can be seen in Table 1, recovery values were satisfactory, ranging between 83 and $106 \%$ with RSD lower than $10 \%$. As it can be seen from the RSD values, the method was reproducible and applicable to the analysis of paclobutrazol in potato and soil.

3.3. Influence of Paclobutrazol Residue in Potato. The residue values of paclobutrazol in potato and soil were listed in Table 2. Foliar spray without cover treatment showed that amounts of paclobutrazol were absorbed by foliage and foliar runoff was absorbed by the soil. Mauk et al. [17] showed result that paclobutrazol residues in the soil increase due to falling 
TABLE 2: Final residues of paclobutrazol in potato and soil.

\begin{tabular}{|c|c|c|c|c|c|}
\hline \multirow{2}{*}{ Sample } & \multirow{2}{*}{ Treatment } & \multirow{2}{*}{ Dosage g (available ingredient)/ha } & \multicolumn{3}{|c|}{ Residues $(\mathrm{mg} / \mathrm{kg} \pm \mathrm{SD}, n=3)$, day after spraying } \\
\hline & & & $22 \mathrm{~d}$ & $32 \mathrm{~d}$ & $40 \mathrm{~d}$ \\
\hline \multirow{6}{*}{ Potato } & \multirow{3}{*}{ Foliar spray without cover } & 40 & $\mathrm{ND}^{\mathrm{a}}$ & ND & ND \\
\hline & & 60 & $0.041 \pm 0.012$ & $0.022 \pm 0.008$ & $0.017 \pm 0.006$ \\
\hline & & 100 & $0.732 \pm 0.028$ & $0.521 \pm 0.022$ & $0.481 \pm 0.017$ \\
\hline & \multirow{3}{*}{ Foliar spray with cover } & 40 & ND & ND & ND \\
\hline & & 60 & ND & ND & ND \\
\hline & & 100 & ND & ND & ND \\
\hline \multirow{6}{*}{ Soil } & \multirow{3}{*}{ Foliar spray without cover } & 40 & $0.081 \pm 0.019$ & $0.032 \pm 0.013$ & $0.021 \pm 0.006$ \\
\hline & & 60 & $0.517 \pm 0.027$ & $0.258 \pm 0.021$ & $0.224 \pm 0.017$ \\
\hline & & 100 & $2.71 \pm 0.23$ & $1.42 \pm 0.17$ & $1.08 \pm 0.12$ \\
\hline & \multirow{3}{*}{ Foliar spray with cover } & 40 & ND & ND & ND \\
\hline & & 60 & ND & ND & ND \\
\hline & & 100 & ND & ND & ND \\
\hline
\end{tabular}

${ }^{\mathrm{a}} \mathrm{ND}$ : not detected.

प TIC of +MRM (2 pairs): from sample 4 (std) of 20150303.wiff (turbo spray)

Max. $3.6 e 4 \mathrm{cps}$

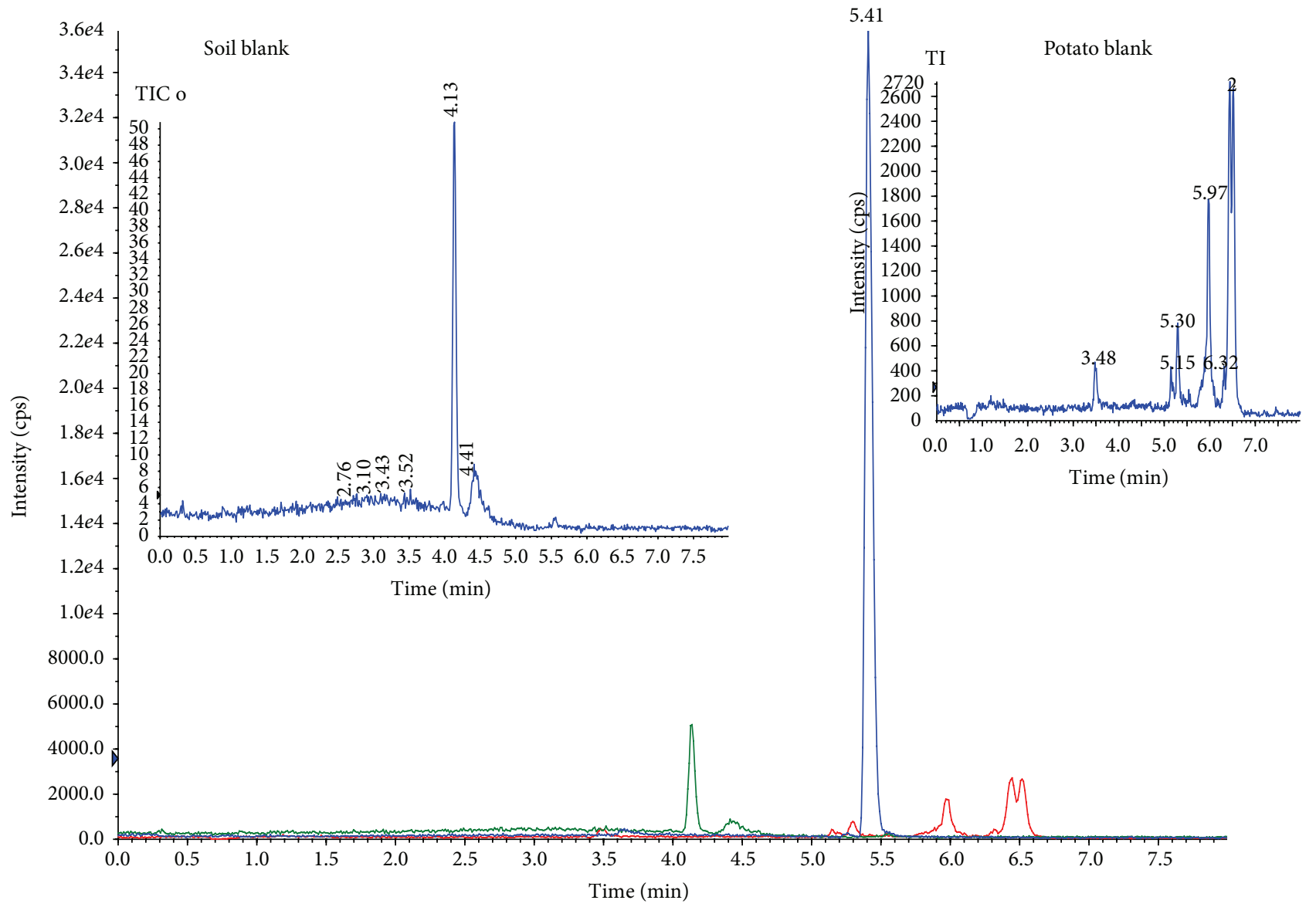

FIGURE 2: Multiple reaction monitor (MRM) chromatograms of paclobutrazol fortified and potato blank and soil blank in quantitative ion, $t$ $=5.41 \mathrm{~min}$ (paclobutrazol).

leaves from nearby sprayed trees. Apparently, the amount of paclobutrazol absorbed by stolon, then transported to tuber, was larger than by foliar absorptive capacity.

To check the possible contamination of paclobutrazol from surface and peel of tuber, the content of paclobutrazol in different treatment was shown in Figure 3. The content in organic solvent was very lower than the expected concentrations in whole potato. The paclobutrazol on surface can be rinsed by distilled water or peeled. So the paclobutrazol residue in potato harvest was mainly from absorption and transport from soil, which was not removed by peeling. 


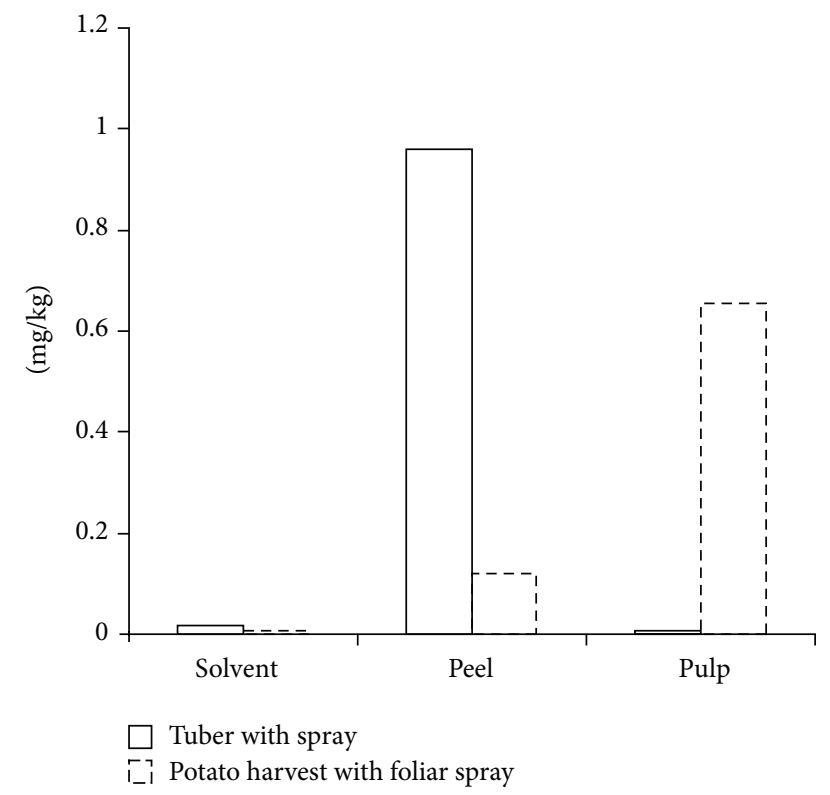

FIGURE 3: The content of paclobutrazol with different treatment after peeling and rinsing.

3.4. Dissipation Rate of Paclobutrazol in Soil. The dissipation curve of paclobutrazol in soil was shown in Figure 4. The result showed that the initial deposits of paclobutrazol in soil were $1.14 \mathrm{mg} / \mathrm{kg}$. Except for a slight increase on 1st day, the residue value showed a steady decrease and was below $0.22 \mathrm{mg} / \mathrm{kg}$ on 50 th day. The half-lives calculated were 20.64 days. The dissipation equation of paclobutrazol was $y=$ $1.0784 e^{-0.037 \mathrm{~d}}, R^{2}=0.9403$.

3.5. Risk Assessment of Paclobutrazol in Potato. To establish a recommended Maximum Residue Limit (MRL) of paclobutrazol in potato, two guideline values, with Need Maximum Daily Intake (NEDI) and Acceptable Daily Intake (ADI), were needed. The value of ADI with paclobutrazol was $0.1 \mathrm{mg} / \mathrm{kg}$ bw/day. NEDA was derived on the supervised trials median residue (STMR) or processing factor (STMR-P) and food intake rate $(F)$. Finally, risk assessment was performed to ensure that the established "safe" level of exposure (MRL) does not exceed the estimated level of actual exposure (ADI).

The equation was

$$
\mathrm{NEDI}=\sum\left[\operatorname{STMR}_{i}\left(\operatorname{STMR}_{i}\right) \times F_{i}\right]
$$

According to the investigation of nutrition and health by Chinese Health Ministry in 2002, the $F$ of potato was $0.0496 \mathrm{~kg}$, STMR in potato harvest (recommended dosage: high dosage level) was $0-0.521 \mathrm{mg} / \mathrm{kg}$, and then the high value NEDI $(0.0258 \mathrm{mg})$ was not beyond $5 \%$ the value ADI $\times 63$ (adult weight) of $6.3 \mathrm{mg}$. Therefore, a MRL in potato was recommended as $1.0 \mathrm{mg} / \mathrm{kg}$.

\section{Conclusion}

Liquid-liquid extraction with low temperature partitioning was developed and validated for analysis of paclobutrazol

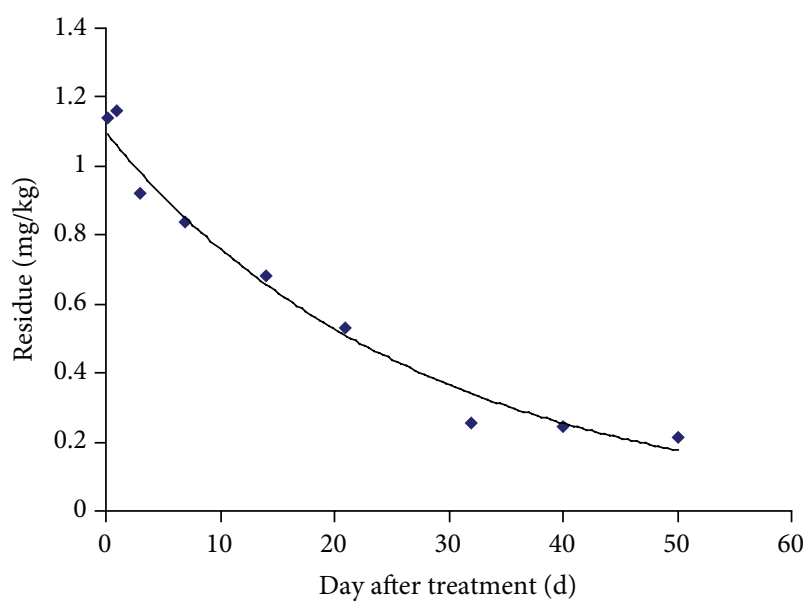

Figure 4: The dynamic dissipation rate of paclobutrazol in soil.

in potato and soil using UHPLC-MS/MS. The optimal chromatographic separation and sensitivity were successfully applied to the analysis of paclobutrazol residue in potato and soil. According to risk assessment with NEDI and ADI, a MRL of paclobutrazol was recommended as $1.0 \mathrm{mg} / \mathrm{kg}$.

\section{Conflict of Interests}

The authors declare that there is no conflict of interests regarding the publication of this paper.

\section{Acknowledgments}

The authors are grateful for the support funded by Social Development Projection of Yunnan province (2012CA 005), talent plan and innovation platform of Yunnan province (2011HB036 and 2014DA001), and quality and safety risk assessment of national Agro Production plan (GJFP201500101 and GJFP201500301).

\section{References}

[1] S. Shimizu-Sato, M. Tanaka, and H. Mori, "Auxin-cytokinin interactions in the control of shoot branching," Plant Molecular Biology, vol. 69, no. 4, pp. 429-435, 2009.

[2] T. Maekawa, M. Maekawa-Yoshikawa, N. Takeda, H. ImaizumiAnraku, Y. Murooka, and M. Hayashi, "Gibberellin controls the nodulation signaling pathway in Lotus japonicus," The Plant Journal, vol. 58, no. 2, pp. 183-194, 2009.

[3] C. S. Mauk, C. R. Unrath, S. M. Blankenship, and G. Yelenosky, "Improved chemical analysis of exogenously-applied 1,2,4triazoles derived from apple tree tissues and soil residues," Acta Horticulturae, vol. 239, pp. 77-80, 1989.

[4] F. Du, G. Ruan, and H. Liu, "Analytical methods for tracing plant hormones," Analytical and Bioanalytical Chemistry, vol. 403, no. 1, pp. 55-74, 2012.

[5] X. Pan and X. Wang, "Profiling of plant hormones by mass spectrometry," Journal of Chromatography B, vol. 877, no. 26, pp. 2806-2813, 2009. 
[6] C. S. Mauk, C. R. Unrath, and S. M. Blankenship, "Rapid quantitative analysis of a gibberellin-sterol inhibitor using high-performance liquid chromatographic cartridge columns," Journal of Plant Growth Regulation, vol. 9, no. 1, pp. 181-184, 1990.

[7] E. A. Stahly and D. A. Buchanan, "Extraction, purification, quantitation of paclobutrazol from fruit tree tissues," HortScience, vol. 21, no. 3, pp. 534-535, 1986.

[8] C. S. Mauk, C. R. Unrath, and S. M. Blankenship, "Development of a strong cation exchange method for purification and HPLC assay of gibberellin-sterol inhibitors in plant tissue," Journal of Chromatographic Science, vol. 28, no. 12, pp. 621-623, 1990.

[9] M. Witchard, "A simplified technique for detection of paclobutrazol in plant sap extracts, using HPLC," Journal of Plant Growth Regulation, vol. 16, no. 4, pp. 213-214, 1997.

[10] C. Bicchi, C. Cordero, P. Rubiolo, and A. Occelli, "Simultaneous determination of six triazolic pesticide residues in apple and pear pulps by liquid chromatography with ultraviolet diode array detection," Journal of AOAC International, vol. 84, no. 5, pp. 1543-1550, 2001.

[11] S.-K. Cho, A. M. Abd El-Aty, K. H. Park et al., "Simple multiresidue extraction method for the determination of fungicides and plant growth regulator in bean sprouts using low temperature partitioning and tandem mass spectrometry," Food Chemistry, vol. 136, no. 3-4, pp. 1414-1420, 2013.

[12] X. Shi, F. Jin, Y. Huang et al., "Simultaneous determination of five plant growth regulators in fruits by modified quick, easy, cheap, effective, rugged, and safe (QuEChERS) extraction and liquid chromatography-tandem mass spectrometry," Journal of Agricultural and Food Chemistry, vol. 60, no. 1, pp. 60-65, 2012.

[13] J. V. Sancho, Ó. J. Pozo, T. Zamora, S. Grimalt, and F. Hernández, "Direct determination of paclobutrazol residues in pear samples by liquid chromatography-electrospray tandem mass spectrometry," Journal of Agricultural and Food Chemistry, vol. 51, no. 15, pp. 4202-4206, 2003.

[14] S. M. Goulart, R. D. Alves, W. X. D. Paula, J. H. D. Queiroz, A. A. Neves, and M. E. L. R. Queiroz, "Determination of carbamates in beverages by liquid-liquid extraction with low temperature partitioning and liquid chromatography," Journal of the Brazilian Chemical Society, vol. 23, no. 6, pp. 1154-1165, 2012.

[15] T. Tekalign and P. S. Hammes, "Growth and biomass production in potato grown in the hot tropics as influenced by paclobutrazol," Plant Growth Regulation, vol. 45, no. 1, pp. 37-46, 2005.

[16] D. Sharma and M. D. Awasthi, "Uptake of soil applied paclobutrazol in mango (Mangifera indica L.) and its persistence in fruit and soil," Chemosphere, vol. 60, no. 2, pp. 164-169, 2005.

[17] C. S. Mauk, C. R. Unrath, S. M. Blankenship, and L. J. Lehman, "Influence of method of application of paclobutrazol on soil residues and growth retardation in a "Starkrimson-Delicious" apple orchard," Plant Growth Regulation, vol. 9, no. 1, pp. 27-35, 1990. 

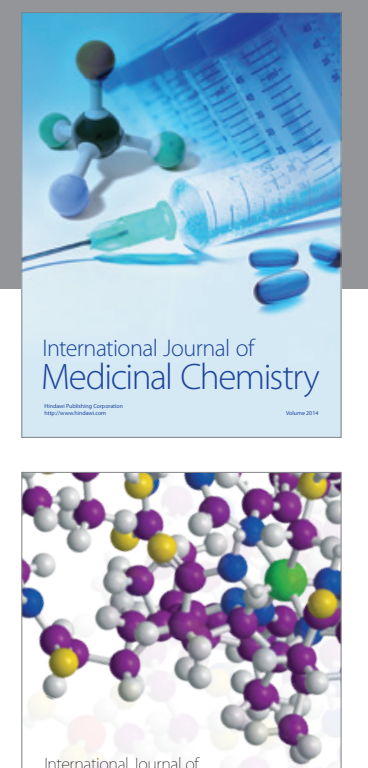

\section{Carbohydrate} Chemistry

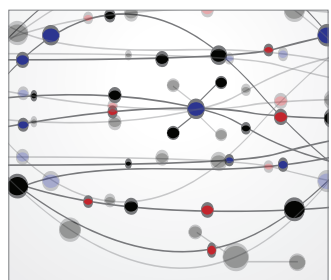

The Scientific World Journal
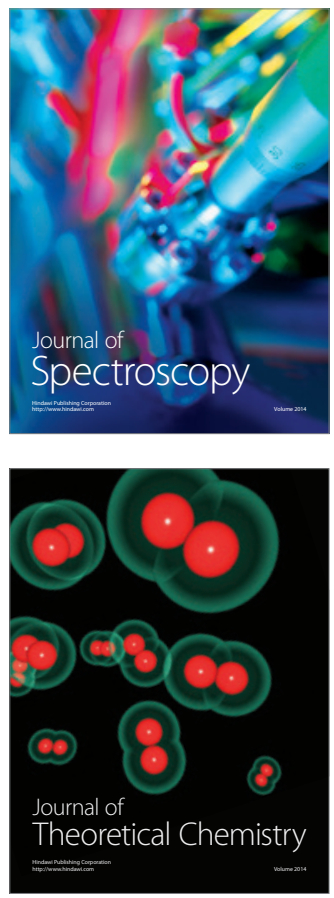
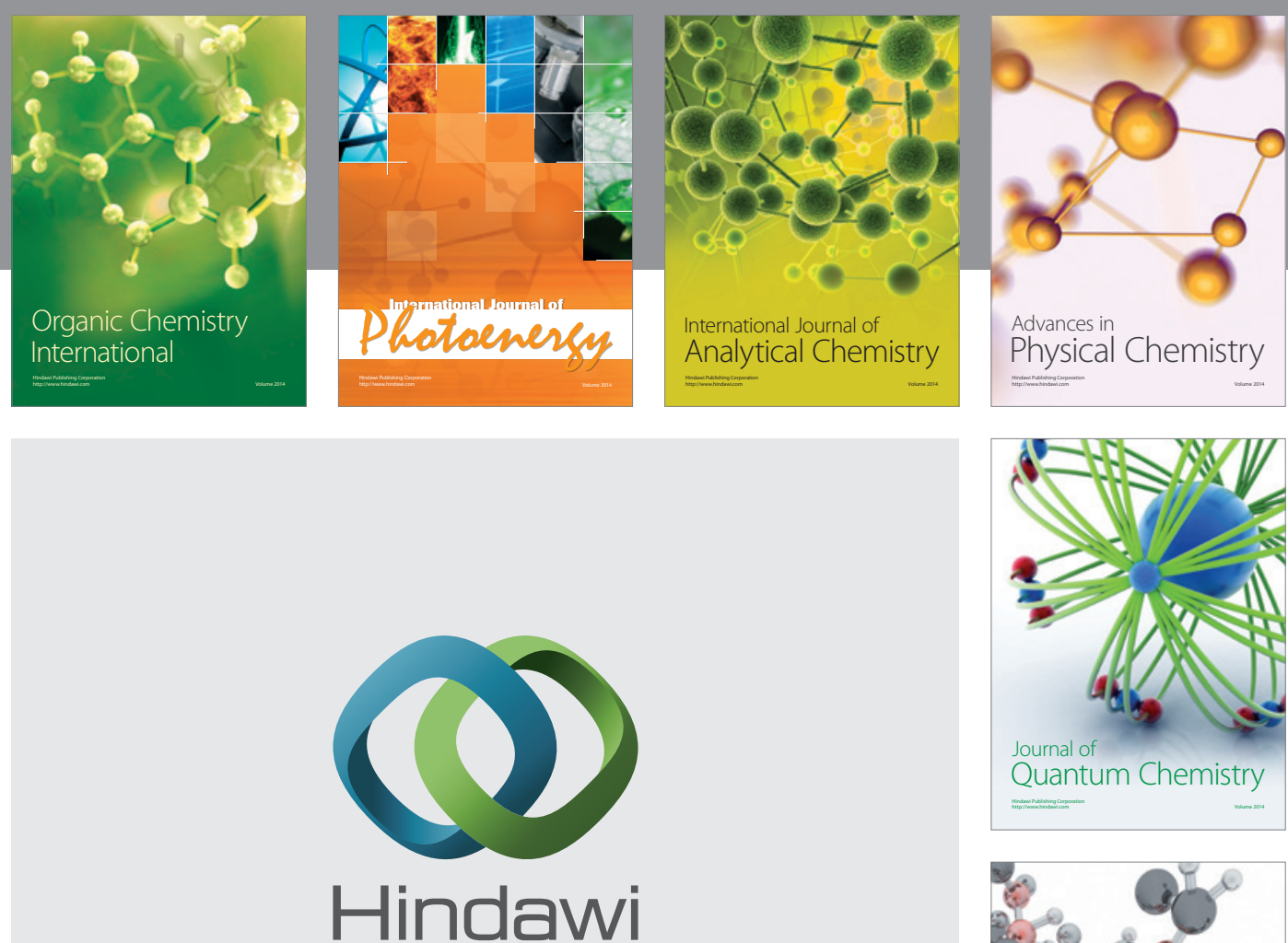

Submit your manuscripts at

http://www.hindawi.com

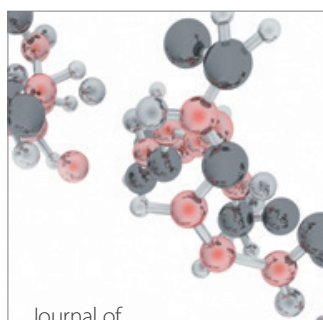

Analytical Methods

in Chemistry

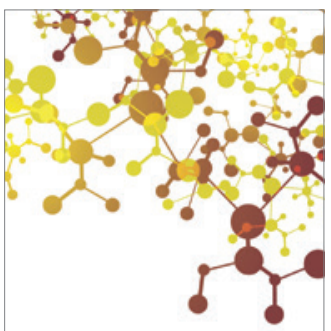

Journal of

Applied Chemistry

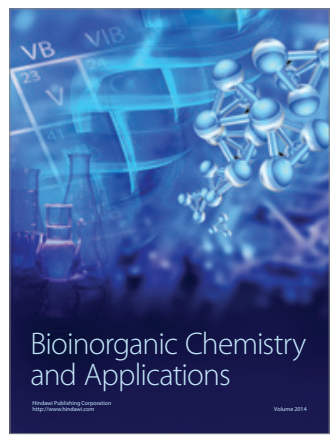

Inorganic Chemistry
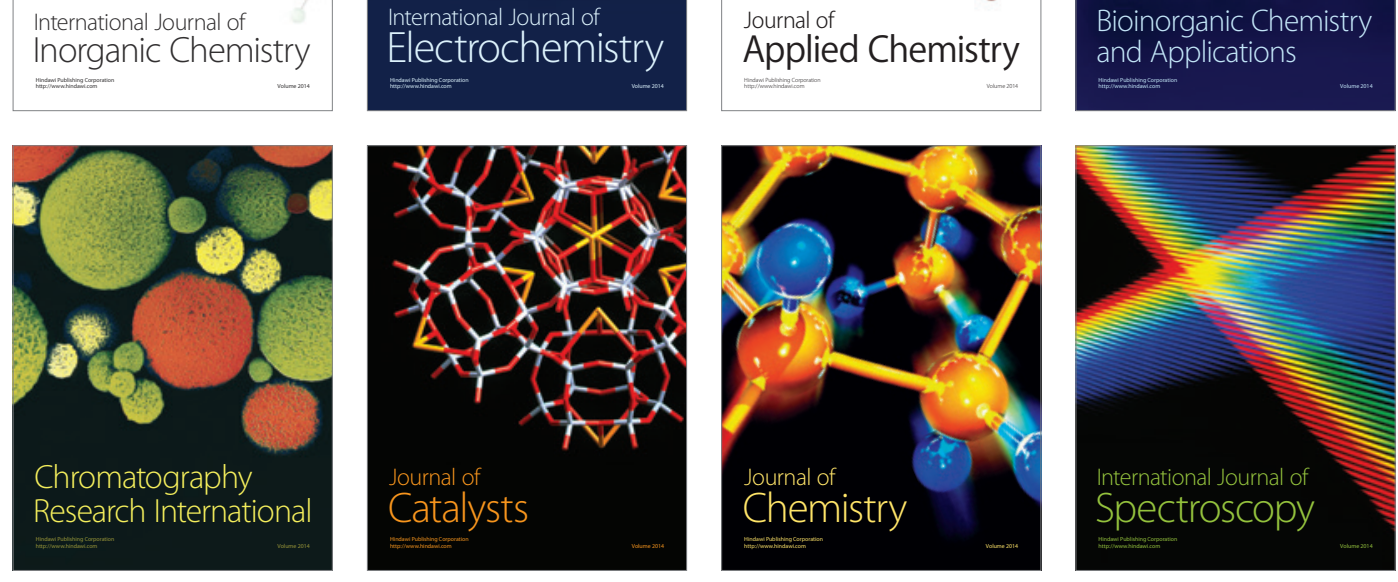